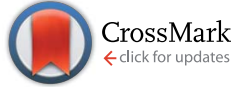

Cite this: Chem. Sci., 2015, 6, 3461

Received 25th March 2015 Accepted 16th April 2015

DOI: $10.1039 / \mathrm{c} 5 \mathrm{sc} 01077 \mathrm{~b}$

www.rsc.org/chemicalscience

\section{Generation of 1,2-azaboretidines via reduction of ADC borane adducts $\uparrow$}

\author{
H. Braunschweig, * A. Gackstatter, T. Kupfer, T. Scheller, F. Hupp, A. Damme, N. Arnold \\ and W. C. Ewing
}

Reaction of the acyclic (diamino)carbene (ADC): $C\left(\mathrm{NiPr}_{2}\right)_{2}(1)$ with different dihaloboranes of the type $\mathrm{RBX}_{2}$ $\left(\mathrm{R}=\right.$ Mes, Dur; $\mathrm{X}=\mathrm{Cl}, \mathrm{Br}$ ) smoothly afforded a novel class of $\mathrm{ADC}$-stabilized borane adducts. For $\mathrm{MesBBr}_{2}$ however, the reaction did not stop at the adduct level, but an uncommon rearrangement process occurred, which eventually resulted in the formation of a 5-membered boracycle after elimination of mesitylene. Chemical reduction of the $\mathrm{ADC}$ borane adducts by $\mathrm{KC}_{8}$ selectively yielded air stable 1,2-azaboretidines. Detailed DFT studies suggest a reduction mechanism involving a highly reactive borylene intermediate, which is converted into the boracycles via a rearrangement/ $\mathrm{C}-\mathrm{H}$ activation sequence.

\section{Introduction}

Recent years have clearly pointed out the exceptional value of carbenes not only as ligands in catalysis, ${ }^{1}$ but also in the stabilization of highly reactive transition metal and main group element species. ${ }^{2}$ Initially, research focused on the use of $\mathrm{N}$ heterocyclic carbenes (A; NHC) as stabilizing Lewis bases, and from 2007 a series of outstanding molecules including diborenes, ${ }^{3}$ diatomic allotropes $\left(\mathrm{B}_{2},{ }^{4} \mathrm{Si}_{2},{ }^{5} \mathrm{Ge}_{2},{ }^{6} \mathrm{Sn}_{2},{ }^{7} \mathrm{P}_{2},{ }^{8} \mathrm{As}_{2}{ }^{9}\right)$, and radical/radical ions $\left(\mathrm{B}, \mathrm{Si}\right.$, pnictogen, organic) ${ }^{2 b}$ could be realized. Later on, it was rapidly recognized that the different electronics of cyclic (alkyl)(amino)carbenes (B; CAAC) can also be quite useful in the generation of such species $\left(\right.$ e.g. $\mathrm{B}_{2},{ }^{10} \mathrm{P}_{2},{ }^{11}$ $\mathrm{PN},{ }^{12} \mathrm{Sb}_{2},{ }^{13} \mathrm{~B} / \mathrm{Si} / \mathrm{P} / \mathrm{Sn}$ radicals). ${ }^{2 e}$ In many cases however, CAAC stabilization also significantly alters the reactivity of the adduct precursors, thereby granting access to other classes of products. $^{2 e}$

The impact of the subtle electronic differences between NHC and CAAC donor ligands is maybe best illustrated by the reduction chemistry of carbene-stabilized haloboranes. Thus, we have demonstrated that chemical reduction of NHC adducts of the type $\mathrm{RBX}_{2} \cdot \mathrm{NHC}$ and $\mathrm{B}_{2} \mathrm{Br}_{4} \cdot \mathrm{NHC}_{2}$ is associated with the generation of boron multiple-bonded species, i.e. diborenes ${ }^{3}$ and diborynes. ${ }^{4}$ By contrast, reduction of DurBCl $\mathrm{D}_{2} \cdot \mathrm{CAAC}(\mathrm{Dur}=$ 2,3,5,6-tetramethylphenyl) stops at the radical stage enabling the isolation of a neutral boron-containing radical, which is most likely a direct consequence of the stronger $\pi$ accepting

Institut für Anorganische Chemie, Julius-Maximilians-Universität Würzburg, Am Hubland, 97074 Würzburg, Germany. E-mail: h.braunschweig@uni-wuerzburg.de; Web: http://www-anorganik.chemie.uni-wuerzburg.de/Braunschweig/

$\dagger$ Electronic supplementary information (ESI) available: Experimental, crystallographic, and computational details. CCDC 1042591-1042594. For ESI and crystallographic data in CIF or other electronic format see DOI: 10.1039/c5sc01077b abilities of the CAAC ligand. ${ }^{\mathbf{1 4}}$ This particular electronic property of the CAAC ligand is also reflected in the cumulenic structure of $\mathrm{B}_{2} \cdot \mathrm{CAAC}_{2}$, which shows a decreased $\mathrm{B}-\mathrm{B}$ bond order in comparison to that of the triply bound $\mathrm{B}_{2} \cdot \mathrm{NHC}_{2} \cdot{ }^{15}$ Fascinating results also come from the group of Bertrand, which highlighted that CAACs efficiently stabilize neutral B-H borylene ${ }^{16}$ and boryl radical species, ${ }^{17}$ as well as boryl anions. ${ }^{18}$

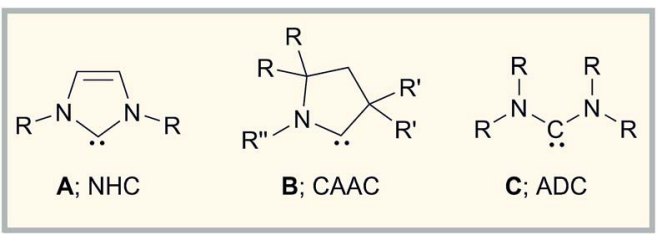

With these developments in mind, we wondered why the potential of acyclic (diamino)carbenes (C; ADC) in the stabilization of uncommon low-valent main group element compounds has not been studied in detail so far. This appears particularly surprising given the remarkable structural and electronic properties of ADCs. ${ }^{19}$ Thus, the wider $\mathrm{N}-\mathrm{C}-\mathrm{N}$ angle in ADCs increases the steric shielding of the carbene carbon atom by the amino substituents, which will also affect the structural environment of any potential bonding partner in providing a larger degree of steric protection to the reactive center. ${ }^{20}$ In addition, ADCs offer a significantly higher basicity, nucleophilicity, and $\sigma$ donor capacity than NHCs, ${ }^{19}$ which might entail other reactivity patterns for the reduction of suitable ADC adducts than those observed for their NHC/CAAC analogs. So far however, ADCs have predominately found application as flexible ligands in transition metal catalysis, ${ }^{19}$ and the number of publications addressing its main group element chemistry is rather limited. Sporadic studies deal with coupling reactions, decomposition reactions, or small molecule activation, ${ }^{\mathbf{1 9 a}, \mathbf{2 1}}$ 
while almost nothing is known about their ability to stabilize reactive main group element compounds.

As part of our ongoing efforts to generate uncommon lowvalent boron species, we now began to study the chemistry of simple ADC borane adducts of the type $\mathrm{RBX}_{2} \cdot \mathrm{ADC}$ with an emphasis on their reduction behavior, and the results are presented in this contribution.

\section{Results and discussion}

We chose bis(diisopropylamino)carbene $\mathbf{1}$ as the most suitable ADC for the realization of ADC borane adducts, because of its high stability and its convenient synthetic access. 1 was first prepared by Alders et al. back in 1996 as the first compound of this class, and can be readily isolated in high yields by sublimation. ${ }^{22}$ The stoichiometric reactions of $\mathbf{1}$ with different dihaloboranes $\mathrm{RBX}_{2}$ (2a: $\mathrm{R}=$ Dur, $\mathrm{X}=\mathrm{Cl}$; 2b: $\mathrm{R}=$ Mes, $\mathrm{X}=\mathrm{Cl}$; 2c: $\mathrm{R}=$ Mes, $\mathrm{X}=\mathrm{Br}$; Mes = 2,4,6-trimethylphenyl) proceeded spontaneously and with high selectivity to afford ADC borane adducts 3a-c in almost quantitative yields (3a: 92\%; 3b: 93\%; 3c: $97 \%$; Scheme 1). Identification of 3a-c posed no difficulties, and ${ }^{11} \mathrm{~B}$ NMR spectroscopy in solution (3a: $\delta=4.8$; 3b: $\delta=4.5$; 3c: $\delta=-1.3$ ) and X-ray diffraction studies on $\mathbf{3 a}$ and $\mathbf{3 b}$ (Fig. 1) clearly confirmed adduct formation, and the presence of tetracoordinate boron centers. The solid-state structures of $\mathbf{3 a}$ and 3b revealed no surprises, and all bonding parameters are reminiscent of other known carbene borane adducts. As anticipated, both structures feature N1-C1-N2 bond angles (3a: $\left.117.0(1)^{\circ} ; 3 \mathbf{b}: 117.1(4)^{\circ}\right)$ that are smaller than in $1\left(121.0(5)^{\circ}\right) .^{22}$

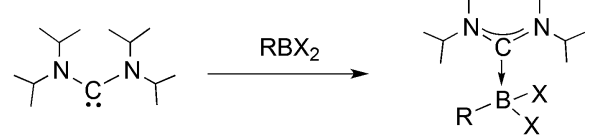

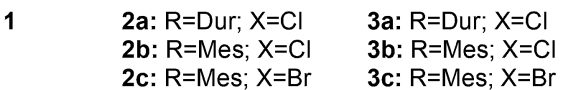

Scheme 1 Syntheses of ADC borane adducts $3 a-c$.

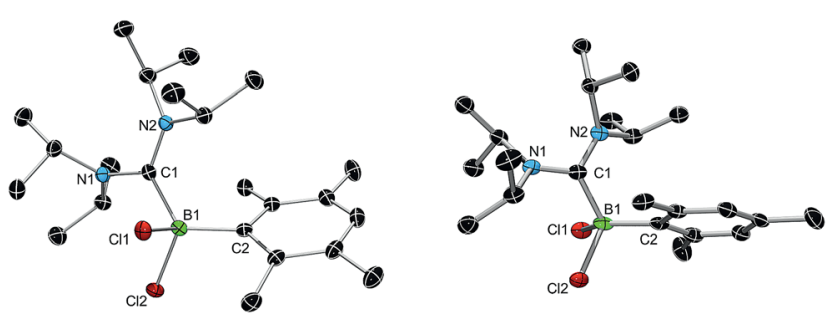

Fig. $1 X$-ray diffraction structures of $3 a$ (left) and $3 b$ (right). Hydrogen atoms and co-crystallized solvent molecules are omitted for clarity. Selected bond lengths $[\AA]$ and angles $\left[{ }^{\circ}\right]$ : 3a: B1-C1 1.681(3), B1-C2 1.622(2), B1-Cl1 1.938(2), B1-Cl2 1.889(2), C1-N1 1.376(2), C1-N2 1.352(2), $\mathrm{C} 1-\mathrm{B} 1-\mathrm{C} 2$ 118.9(1), $\mathrm{Cl1}-\mathrm{B} 1-\mathrm{Cl} 2$ 103.71(9), N1-C1-N2 117.0(2); 3b: B1-C1 1.676(5), B1-C2 1.623(5), B1-Cl1 1.910(4), B1-Cl2 1.920(4), C1-N1 1.364(5), C1-N2 1.365(4), C1-B1-C2 113.5(3), $\mathrm{Cl} 1-\mathrm{B} 1-\mathrm{Cl} 2$ 101.4(2), N1-B1-N2 116.6(3).

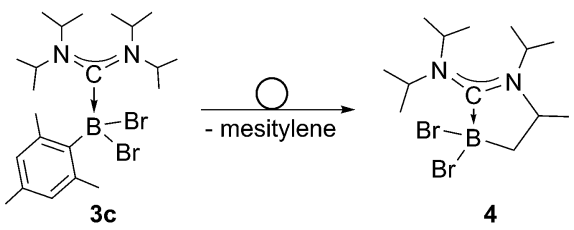

Scheme 2 Rearrangement of ADC borane adduct 3c.

While $\mathbf{3 a}$ and $\mathbf{3 b}$ were found indefinitely stable under inert conditions, $3 c$ readily undergoes a rearrangement reaction to afford boracycle 4 (Scheme 2). The process occurs both in solution ( $24 \mathrm{~h}$ ), and in the solid-state (4-5 days), and is quantitative as judged by ${ }^{1} \mathrm{H}$ NMR and ${ }^{11} \mathrm{~B}$ NMR spectroscopy (3c: $\delta=$ $-1.3 ; 4: \delta=-3.4)$. From a mechanistic point of view, rearrangement of $3 \mathbf{c}$ involves $\mathrm{C}-\mathrm{H}$ activation of one iPr group with concomitant elimination of mesitylene to generate the 5membered heterocycle $\mathbf{4}$, whose identity was eventually verified by an X-ray diffraction study (Fig. 2). As a consequence of ring formation, the N1-C1-N2 angle $\left(122.8(2)^{\circ}\right)$ in 4 is slightly larger than in adducts $3 \mathbf{a}\left(117.0(1)^{\circ}\right)$ and $3 \mathbf{b}\left(117.1(4)^{\circ}\right)$, while the C1-B1-C2 angle $\left(99.53(1)^{\circ}\right)$ becomes dramatically smaller (3a: $118.9(1)^{\circ}$; 3b: $\left.113.5(3)^{\circ}\right)$. By contrast, the C1-N1 (1.352(2) ̊) and C1-N2 (1.340(2) ̊) bond lengths remain almost unaffected ( $c f$.

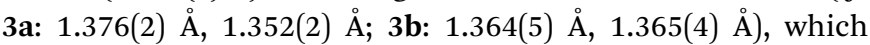
suggests that the carbenic character of $\mathrm{C} 1$ is retained upon rearrangement. The elimination of mesitylene induced by the coordination of the ADC to the boron center of $\mathbf{3 c}$ is highly unexpected and should definitely be emphasized here. To the best of our knowledge, such a behavior has not been observed before in boron chemistry. All cases that report on somekind of rearrangement/elimination processes upon coordination of a $\sigma$ donor to a haloborane were accompanied exclusively by $\mathrm{HX}$ elimination ( $\mathrm{X}=\mathrm{Br}, \mathrm{I}$ ), which usually seems to be strongly favored over $\mathrm{RH}$ elimination. ${ }^{23}$

Next, we studied the reduction chemistry of ADC borane adducts 3a-c. To this end, 3a was treated with an excess of $\mathrm{KC}_{8}$ in benzene solution (Scheme 3). Initially, the reaction mixture turned red in color, which however completely disappeared within one hour to finally leave a colorless solution. ${ }^{11} \mathrm{~B}$ NMR spectroscopy indicated quantitative and selective conversion of

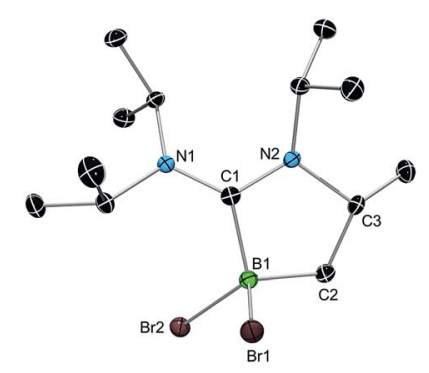

Fig. 2 X-ray diffraction structure of 4 . Hydrogen atoms are omitted for clarity. Selected bond lengths $[\AA \AA]$ and angles $\left[{ }^{\circ}\right]$ : B1-C1 1.624(2), $\mathrm{B} 1-\mathrm{C} 2$ 1.598(3), B1-Br1 2.049(2), B1-Br2 2.067(2), C1-N1 1.352(2), C1-N2 1.340(2), N2-C3 1.507(2), C2-C3 1.532(2), C1-B1-C2 99.53(1), $\mathrm{B} 1-\mathrm{C} 2-\mathrm{C} 3$ 104.3(1), C2-C3-N2 104.5(1), C3-N2-C1 113.3(1), N2-C1-B1 109.0(2), N1-C1-N2 122.8(2). 


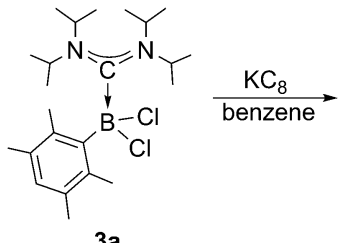

3a

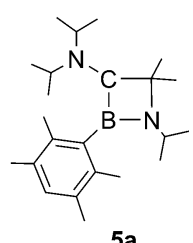

Scheme 3 Synthesis of 1,2-azaboretidine 5a.

3a into a new boron-containing species (5a: $\delta=45.0)$. After work-up, 1,2-azaboretidine $\mathbf{5 a}$ was isolated as air stable, colorless crystals by recrystallization from hexanes.

X-ray diffraction served to validate the molecular composition of $5 \mathbf{a}$ in the solid-state (Fig. 3). Accordingly, reduction of 3a is followed by a 1,2-shift of one $\mathrm{NiPr}_{2}$ moiety from the carbenic carbon $\mathrm{C} 1$ to the boron center, and a subsequent $\mathrm{C}-\mathrm{H}$ activation/ring closure sequence to afford the 4-membered heterocycle 5a. The structural parameters of 5a are fully consistent with a classification as 1,2-azaboretidine, and relevant bond lengths and angles lie within the same range observed for other 1,2-azaboretidines. ${ }^{24}$ Thus, the boron center adopts a distorted trigonal planar geometry. The C1-B1-N1 angle of 91.1(2) indicates the presence of an almost regular $\mathrm{BC}_{2} \mathrm{~N}$ rectangle (B1-N1-C3: 96.0(2) ; N1-C3-C1: 88.5(2) ${ }^{\circ}$; C3-C1-B1: 83.8(2) ${ }^{\circ}$, which however is not completely planar (torsion angles between $-5.0(2)^{\circ}$ and $\left.4.9(2)^{\circ}\right)$. Due to the $\mathrm{C}-\mathrm{H}$ activation event involving the carbene center of $\mathbf{3 a}$, the geometry of $\mathrm{C} 1$ changed from trigonal planar in 3a to highly distorted tetrahedral in $\mathbf{5 a}$ (B1-C1-N2: 128.0(3) $)^{\circ}$.

The use of ADC 1 has been previously implicated in the formation of 4-membered rings in its reaction with $\mathrm{CO}$, wherein initial complexation of $\mathrm{CO}$ and resultant ketene formation leads to the migration of one of the two $\mathrm{ADC} \mathrm{NiPr} 2$ groups across the $\mathrm{C}=\mathrm{C}$ bond, initially forming an amide complex that subsequently cyclizes to the final $\beta$-lactam product. ${ }^{21 b, 25} \mathrm{~A}$ similar mechanism can be invoked to explain the formation of the 1,2azaboretidine, since the initial reduction of $\mathbf{3 a}$ presumably yields a high-energy borylene ( $\mathrm{ADC}=\mathrm{B}-\mathrm{Dur}$ ), analogous to the aforementioned ketene $(\mathrm{ADC}=\mathrm{C}=\mathrm{O})$.

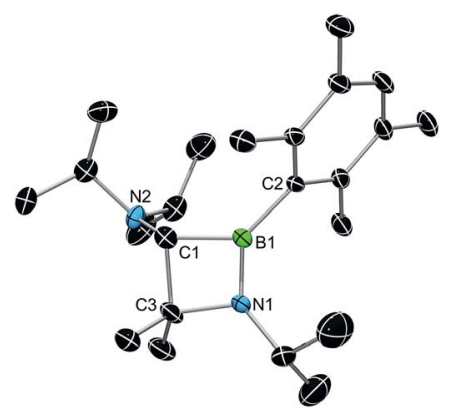

Fig. 3 X-ray diffraction structure of $5 a$. Hydrogen atoms are omitted for clarity. Selected bond lengths $[\AA]$ and angles [ $\left.{ }^{\circ}\right]$ : B1-C1 1.624(4), $\mathrm{B} 1-\mathrm{C} 2$ 1.577(4), B1-N1 1.398(4), C1-N2 1.446(4), C1-C3 1.599(5), C3-N1 1.498(4); C1-B1-N1 91.1(2), B1-N1-C3 96.0(2), N1-C3-C1 88.5(2), C3-C1-B1 83.8(2), B1-C1-N2 128.0(3).

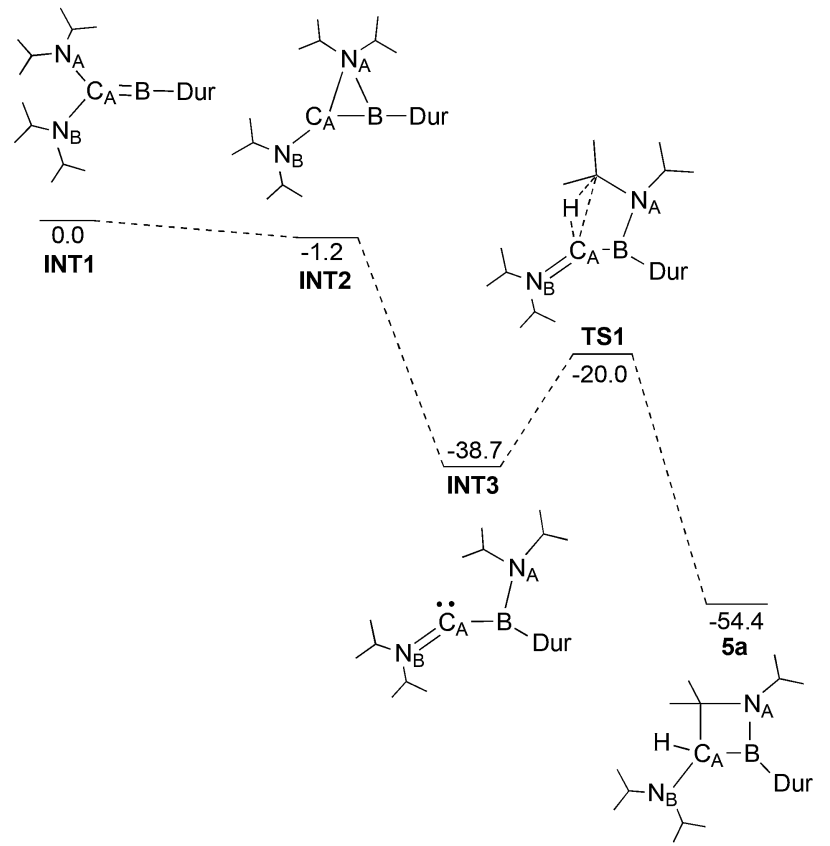

Fig. 4 Proposed reaction pathway from the initial borylene product of the reduction of $3 a$ to $5 a$, as calculated by DFT (B3LYP/6-311G(d)). Electronic energies are given in $\mathrm{kcal} \mathrm{mol}^{-1}$ and are ZPE-corrected.

Through DFT calculations (B3LYP/6-311G(d)) we were able to investigate such a mechanism (Fig. 4). A structure for the postreduction high energy borylene was successfully identified (INT1), showing a linear $\mathrm{C}_{\mathrm{A}}-\mathrm{B}-\mathrm{C}_{\mathrm{Dur}}$ unit $\left(175.0^{\circ}\right)$, as well as one wide and one more acute $\mathrm{N}-\mathrm{C}-\mathrm{B}$ angle $\left(\mathrm{N}_{\mathrm{A}}-\mathrm{C}_{\mathrm{A}}-\mathrm{B}: 106.8^{\circ}\right.$; $\left.\mathrm{N}_{\mathrm{B}}-\mathrm{C}_{\mathrm{A}}-\mathrm{B}: 134.3^{\circ}\right)$. The transition states in the migration of the diisopropylamine could not be located, likely as a result of the shallow potential energy surface in this region, but an intermediate was found with $\mathrm{N}_{\mathrm{A}}$ bridging $\mathrm{C}_{\mathrm{A}}$ and $\mathrm{B}$ (INT2) only $1.2 \mathrm{kcal} \mathrm{mol}^{-1}$ lower in energy than INT1. Completion of the migration of the diisopropylamine group from $\mathrm{C}_{\mathrm{A}}$ to $\mathrm{B}$ (INT3) results in a large decrease in energy $\left(-37.5 \mathrm{kcal} \mathrm{mol}^{-1}\right)$, giving a structure with a planar boron $\left(\Sigma_{\text {angles }}=359.5^{\circ}\right)$, but a pronounced bend at $\mathrm{C}_{\mathrm{A}}\left(\mathrm{B}-\mathrm{C}_{\mathrm{A}}-\mathrm{N}_{\mathrm{B}}: 143.4^{\circ}\right)$ and a short $\mathrm{C}_{\mathrm{A}}-\mathrm{N}_{\mathrm{B}}$ bond $(1.282 \AA)$. Activation of the central $\mathrm{C}-\mathrm{H}$ bond on one of the two iPr groups on $\mathrm{N}_{\mathrm{A}}$ presumably leads to TS1, $18.7 \mathrm{kcal} \mathrm{mol}^{-1}$

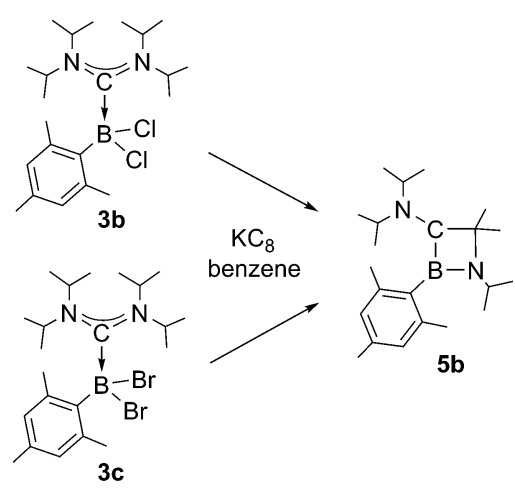

Scheme 4 Synthesis of 1,2-azaboretidine 5a. 
higher in energy than INT3, but still $20.0 \mathrm{kcal} \mathrm{mol}^{-1}$ lower in energy than the initial borylene. Given the high activation barrier for this rearrangement process however, a mechanism involving boron-based radical intermediates might also be effective at this stage, even though we did not obtain any definite experimental evidence for the presence of such radical species. Completion of the $\mathrm{C}-\mathrm{H}$ activation gives compound $\mathbf{5 a}$, $54.4 \mathrm{kcal} \mathrm{mol}^{-1}$ lower in energy than the borylene product of the reduction of $\mathbf{3 a}$.

Chemical reduction of ADC borane adducts $\mathbf{3 b}$ and $\mathbf{3 c}$ pursues an identical reaction pathway as observed for $\mathbf{3 a}$ (Scheme 4), and in both cases 1,2-azaboretidine $\mathbf{5 b}$ is formed with high selectivity as suggested by ${ }^{11} \mathrm{~B}$ NMR spectroscopy of the reaction mixtures $(\delta=44.9)$. 5b can only be isolated as an colorless oil after the standard work-up procedure, which precluded a determination of its molecular structure by X-ray diffraction. The results of NMR spectroscopic studies and an elemental analysis however clearly legitimate the assigned composition.

\section{Conclusions}

In summary, we have demonstrated that the ADC borane adducts $3 \mathbf{3 a - c}$ are conveniently accessible by stoichiometric reaction of dihaloboranes $\mathrm{RBX}_{2}$ with bis(diisopropylamino)carbene $\mathbf{1}$. While the chloro-substituted species $\mathbf{3 a}$ and $\mathbf{3 b}$ were found indefinitely stable under ambient conditions, the bromosubstituted derivative $3 \mathbf{c}$ was prone to undergo a rearrangement process both in solution, and in the solid-state to afford the 5membered heterocycle 4 via $\mathrm{C}-\mathrm{H}$ activation and mesitylene elimination steps. Subsequent chemical reduction of the ADC borane adducts 3a-c led to the formation of air stable 1,2-azaboretidines $\mathbf{5 a}$ and $\mathbf{5 b}$. According to DFT calculations, this transformation most likely involves the initial formation of a reactive borylene species, which is converted into the heterocyclic products by a sequence of $1,2-\mathrm{NiPr}_{2}$-shift and $\mathrm{C}-\mathrm{H}$ activation/ring closure.

\section{Acknowledgements}

This work was supported by the Deutsche Forschungsgemeinschaft.

\section{Notes and references}

1 For special issues on this topic, see for instance: $(a)$ T. Rovis and S. P. Nolan, Synlett, 2013, 24, 188; (b) A. J. Arduengo and G. Bertrand, Chem. Rev., 2009, 109, 3209; (c) X. Bugaut and D. Glorius, Chem. Soc. Rev., 2012, 41, 3511.

2 See for instance: (a) Y. Wang and G. H. Robinson, Dalton Trans., 2012, 41, 337; (b) C. D. Martin, M. Soleilhavoup and G. Betrand, Chem. Sci., 2013, 4, 3020; (c) H. Braunschweig and R. D. Dewhurst, Organometallics, 2014, 33, 6271; (d) Y. Wang and G. H. Robinson, Inorg. Chem., 2014, 53, 11815; (e) M. Soleilhavoup and G. Bertrand, Acc. Chem. Res., 2015, 48, 256.
3 (a) P. Bissinger, H. Braunschweig, A. Damme, T. Kupfer and A. Vargas, Angew. Chem., Int. Ed., 2012, 51, 9931; (b) P. Bissinger, H. Braunschweig, A. Damme, T. Kupfer, I. Krummenacher and A. Vargas, Angew. Chem., Int. Ed., 2014, 53, 5689; (c) H. Braunschweig, R. D. Dewhurst, C. Hörl, A. K. Phukan, F. Pinzner and S. Ullrich, Angew. Chem., Int. Ed., 2014, 53, 3241; (d) P. Bissinger, H. Braunschweig, A. Damme, C. Hörl, I. Krummenacher and T. Kupfer, Angew. Chem., Int. Ed., 2015, 54, 359; (e) P. Bissinger, A. Steffen, A. Vargas, R. D. Dewhurst, A. Damme and H. Braunschweig, Angew. Chem., Int. Ed., 2015, 54, 4362.

4 (a) H. Braunschweig, R. D. Dewhurst, K. Hammond, J. Mies, K. Radacki and A. Vargas, Science, 2012, 336, 1420; (b) H. Braunschweig, T. Dellermann, R. D. Dewhurst, W. C. Ewing, K. Hammond, J. O. C. Jimenez-Halla, T. Kramer, I. Krummenacher, J. Mies, A. K. Phukan and A. Vargas, Nat. Chem., 2013, 5, 1025.

5 Y. Wang, Y. Xie, R. B. King, P. Wei, H. F. Schaefer III, P. v. R. Schleyer and G. H. Robinson, Science, 2008, 321, 1069.

6 A. Sidiropoulos, C. Jones, A. Stasch, S. Klein and G. Frenking, Angew. Chem., Int. Ed., 2009, 48, 9701.

7 C. Jones, A. Sisiropoulos, N. Holzmann, G. Frenking and A. Stasch, Chem. Commun., 2012, 48, 9855.

8 Y. Wang, Y. Xie, P. Wei, R. B. King, H. F. Schaefer III, P. v. R. Schleyer and G. H. Robinson, J. Am. Chem. Soc., 2008, 130, 14970.

9 M. Y. Abraham, Y. Wang, Y. Xie, P. Wei, H. F. Schaefer III, P. v. R. Schleyer and G. H. Robinson, Chem.-Eur. J., 2010, 16, 432 .

10 (a) J. Böhnke, H. Braunschweig, W. C. Ewing, C. Hörl, T. Kramer, I. Krummenacher, J. Mies and A. Vargas, Angew. Chem., Int. Ed., 2014, 53, 9082; (b) J. Böhnke, H. Braunschweig, P. Constantinidis, T. Dellermann, W. C. Ewing, I. Fischer, K. Hammond, F. Hupp, J. Mies, H.-C. Schmitt and A. Vargas, J. Am. Chem. Soc., 2015, 137, 1766; (c) J. Böhnke, H. Braunschweig, T. Dellermann, W. C. Ewing, T. Kramer, I. Krummenacher and A. Vargas, Angew. Chem., Int. Ed., 2015, 54, 4469.

11 O. Back, G. Kuchenbeiser, B. Donnadieu and G. Bertrand, Angew. Chem., Int. Ed., 2009, 48, 5530.

12 R. Kinjo, B. Donnadieu and G. Bertrand, Angew. Chem., Int. Ed., 2010, 49, 5930.

13 R. Kretschmer, D. A. Ruiz, C. E. Moore, A. L. Rheingold and G. Bertrand, Angew. Chem., Int. Ed., 2014, 53, 8176.

14 P. Bissinger, H. Braunschweig, A. Damme, I. Krummenacher, A. K. Phukan, K. Radacki and S. Sugawara, Angew. Chem., Int. Ed., 2014, 53, 7360.

15 F. A. Perras, W. C. Ewing, T. Dellermann, J. Böhnke, S. Ulrich, T. Schäfer, H. Braunschweig and D. L. Bryce, Chem. Sci., 2015, 6, DOI: 10.1039/c5sc00644a.

16 R. Kinjo, B. Donnadieu, M. Ali Celik, G. Frenking and G. Bertrand, Science, 2011, 333, 610.

17 F. Dahcheh, D. Martin, D. W. Stephan and G. Bertrand, Angew. Chem., Int. Ed., 2014, 53, 13159.

18 D. A. Ruiz, G. Ung, M. Melaimi and G. Bertrand, Angew. Chem., Int. Ed., 2013, 52, 7590. 
19 (a) J. Vignolle, X. Cattöen and D. Bourissou, Chem. Rev., 2009, 109, 3333; (b) D. Kremzow, G. Seidel, C. W. Lehmann and A. Fürstner, Chem.-Eur. J., 2005, 11, 1833; (c) B. Dhudshia and A. N. Thadani, Chem. Commun., 2006, 6, 668; (d) A. G. Tskhovrebov, K. V. Luzyanin, M. L. Kuznetsov, V. N. Sorokoumov, I. A. Balova, M. Haukka and V. Y. Kukushin, Organometallics, 2011, 30, 863; (e) C. Bartolomé, Z. Ramiro, P. Pérez-Galán, C. Bour, M. Raducan, A. M. Echavarren and P. Espinet, Inorg. Chem., 2008, 47, 11391; (f) C. Bartolomé, Z. Ramiro, D. García-Cuadrado, P. Pérez-Galán, M. Raducan, C. Bour, A. M. Echavarren and P. Espinet, Organometallics, 2010, 29, 951; $(g)$ H. Seo, B. P. Roberts, K. A. Abboud, K. M. Merz Jr and S. Hong, Org. Lett., 2010, 21, 4860; (h) V. P. Boyarskiy, K. V. Luzyanin and V. Y. Kukushkin, Coord. Chem. Rev., 2012, 256, 2029; (i) L. M. Slaughter, ACS Catal., 2012, 2, 1802.

20 (a) W. A. Herrmann, K. Öfele, D. v. Preysing and E. Herdtweck, J. Organomet. Chem., 2003, 684, 235; (b) E. L. Rosen, M. D. Sanderson, S. Saravanakumar and C. W. Bielawski, Organometallics, 2007, 26, 5774; (c) K. Denk, P. Sirsch and W. A. Herrmann, J. Organomet.
Chem., 2002, 649, 219; (d) G. D. Frey, E. Herdtweck and A. Herrmann, J. Organomet. Chem., 2006, 691, 2465.

21 (a) T. Schulz, M. Leibold, C. Färber, M. Maurer, T. Porsch, M. C. Holthausen and U. Siemeling, Chem. Commun., 2012, 48, 9123; (b) T. Schulz, C. Färber, M. Leibold, C. Bruhn, W. Baumann, D. Selent, T. Porsch, M. C. Holthausen and U. Siemeling, Chem. Commun., 2013, 49, 6834.

22 R. W. Alder, P. R. Allen, M. Murray and A. G. Orpen, Angew. Chem., Int. Ed., 1996, 35, 1121.

23 (a) P. Bissinger, H. Braunschweig, A. Damme, R. D. Dewhurst, T. Kupfer, K. Radacki and K. Wagner, J. Am. Chem. Soc., 2011, 133, 19044; (b) H. Braunschweig, A. Damme and T. Kupfer, Chem. Commun., 2013, 49, 2774.

24 (a) S. Channareddy, B. Glaser, E. P. Mayer, H. Nöth and S. W. Helm, Chem. Ber., 1993, 126, 1119; (b) M. Suginome, T. Fukuda and Y. Iko, J. Organomet. Chem., 2002, 643-644, 508.

25 U. Siemeling, C. Färber, C. Bruhn, M. Leibold, D. Selent, W. Baumann, M. v. Hopffgarten, C. Goedecke and G. Frenking, Chem. Sci., 2010, 1, 697. 